ORIGINAL PAPER

\title{
SPECTRUM OF BIOPSY-PROVEN RENAL DISEASES IN PATIENTS With TYPe 2 Diabetes mellitus. A Single CENTER STUDY
}

\author{
Mazgorzata Wąrowska-DanilewicZ ${ }^{1}$, Marian Danilewicz ${ }^{2}$
}

${ }^{1}$ Department of Nephropathology, Medical University of Lodz, Lodz, Poland

${ }^{2}$ Department of Pathomorphology, Medical University of Lodz, Lodz, Poland

\begin{abstract}
This is the first report from Poland documenting biopsy-proven renal diseases in type 2 diabetes mellitus. We analyzed the data of 76 patients with type 2 diabetes who underwent renal biopsy and were diagnosed in the Department of Nephropathology, Medical University of Lodz. The patients were divided into the following three groups according to the histological diagnosis: group I - isolated non-diabetic renal disease (NDRD); group II - NDRD superimposed on underlying diabetic nephropathy (NDRD + DN); and group III - isolated diabetic nephropathy (DN). Non-diabetic renal disease was found in 38 patients (50\%), non-diabetic renal disease superimposed on underlying diabetic nephropathy was diagnosed in 11 patients (14.5\%), and isolated diabetic nephropathy was seen in 27 patients (35.5\%). The most common glomerular lesion found in groups I and II was focal segmental glomerulosclerosis (FSGS). On the basis of clinical and laboratory parameters, differentiating NDRD from DN in diabetic patients is not always obvious. However, our study revealed that hematuria, short duration of diabetes and the absence of diabetic retinopathy in type 2 diabetic patients manifesting renal involvement may suggest NDRD. The only way to distinguish NDRD from DN is histological evaluation of renal tissue.
\end{abstract}

Key words: diabetic nephropathy, non-diabetic renal disease, renal biopsy.

\section{Introduction}

The prevalence of diabetes mellitus (DM) has been increasing worldwide, and diabetic nephropathy $(\mathrm{DN})$ has become the leading cause of end stage renal disease (ESRD) [1]. According to the World Health Organization, the number of diabetics in Poland will increase to 2.2-2.5 million by 2030 [2]. Type 2 diabetes constitutes the majority of cases of diabetes, and accounts for $85 \%$ to $90 \%$ of all carbohydrate metabolism disorders. The pathogenetic mechanisms involved in the initiation and progression of renal injury in diabetic nephropathy are multifactorial. They include renal hemodynamic abnormalities, particularly elevated glomerular filtration rate (GFR), cap- illary hydraulic pressure, and persistent hyperglycemia, which induces biochemical abnormalities in the polyol pathway and participates in the formation of advanced products of nonenzymatic glycosylation. Diabetic nephropathy causes injury to each of the cell types in the glomerular tuft [1]. However, injury to the podocytes is crucial for the progression to glomerulosclerosis [3]. The characteristic clinical lesions of diabetic nephropathy encompass heavy proteinuria, hypertension, and renal failure. The most characteristic lesions seen in DN are nodular or diffuse glomerulosclerosis, expansion of mesangium, capillary wall thickening and arteriolar hyalinosis; however, it must be taken into consideration that renal diseases other than diabetic glomerulosclerosis can 
occur in diabetic patients. On the other hand, diabetic nephropathy is the most common glomerular lesion that may be complicated by another form of glomerulonephritis. Among patients with type 2 diabetes who had renal biopsy, the prevalence of NDRD varied in the published literature, from $12 \%$ to $79 \%$ $[4,5,6,7,8,9,10]$. It is thought that approximately $33 \%$ of biopsies with diabetic nephropathy have superimposed glomerular diseases. Mazzucco et al. [10] found that at a centre where biopsies were performed in patients with proteinuria $>0.5 \mathrm{~g} /$ day regardless of renal dysfunction or hematuria, 64 of 193 type 2 diabetics had nondiabetic glomerular disease, 43 of which were superimposed on diabetic glomerulosclerosis. Concurrent diabetic glomerulosclerosis and membranous glomerulonephritis are the most commonly reported dual glomerular diagnoses [11]. Pathologic evaluation of renal tissue can discriminate diabetic nephropathy from nondiabetic renal disease (NDRD), but nephrologists are often reluctant to perform renal biopsy in patients with diabetes mellitus owing to the potential risk of the procedure. A renal biopsy is generally reserved for diabetic patients who show recent worsening of proteinuria, hematuria or acute renal failure. It should be stressed that discernment of NDRD from diabetic nephropathy is of considerable importance, because the early treatment of renal diseases other than DN in diabetics may reduce progression of chronic kidney disease to ESRD. The aim of the study was to evaluate the incidence of non-diabetic renal disease, non-diabetic renal disease superimposed on underlying diabetic nephropathy and isolated diabetic glomerulosclerosis in patients with type 2 diabetes mellitus. Another purpose was to analyze clinical and laboratory data in relation to histopathology findings. It should be highlighted that this is the first report documenting biopsy-proven renal disease in patients with type 2 diabetes mellitus in Poland.

\section{Material and methods}

The material consisted of kidney biopsies obtained for diagnostic purposes from 76 adult patients ( 52 males and 24 females, mean age \pm SD: $57 \pm 9.4$ years) with type 2 diabetes mellitus who had undergone renal biopsy between January 2006 and February 2013, and were diagnosed in the Department of Nephropathology, Medical University of Lodz. Patient age, gender, duration of diabetes, presence of diabetic retinopathy, hypertension, nephrotic syndrome, urinary protein excretion, hematuria, glomerular filtration rate (GFR), and the value of body mass index (BMI) were noted at the time of renal biopsy. The duration of diabetes was defined as the period between the age at onset and age at performing renal biopsy. Hypertension was defined as blood pressure more than $140 / 90 \mathrm{mmHg}$. Indications for renal biopsy were the presence of acute renal insufficiency, hematuria or massive proteinuria.

In all cases renal biopsy specimens were routinely processed by light microscopy, immunofluorescence and electron microscopy. The samples were embedded in paraffin and sectioned at $2 \mu \mathrm{m}$, followed by HE, Masson, periodic acid-Schiff, periodic acid-silver methenamine, and Congo red staining. For immunofluorescence study the samples were sectioned in frozen conditions, followed by staining for $\operatorname{IgG}, \operatorname{IgA}$, IgM, C3, C1q, kappa and lambda light chain. The electron microscopy observations were done with JEM 1011 electron microscopy after routine staining. Diabetic nephropathy was diagnosed by experienced renal pathologists by the presence of expansion and intercapillary glomerulosclerosis, with or without the nodular Kimmelstiel-Wilson formation, basement membrane thickening, fibrin caps or capsular drops and arteriolar hyalinosis, supported by immunofluorescence study and electron microscope findings. Pathologic lesions in DN were classified according to the pathologic classification of diabetic nephropathy [12]. Non-diabetic renal disease was categorized following orthodox criteria [13]. On the basis of histology findings the patients were grouped into one of the three categories: group I - isolated non-diabetic renal disease (NDRD); group II - NDRD superimposed on underlying diabetic nephropathy (NDRD $+\mathrm{DN})$; and group III - isolated diabetic nephropathy (DN).

\section{Statistics}

All values are expressed as mean \pm standard deviation (SD) or percentages. The differences between groups were assessed using the Mann-Whitney $U$ test. The univariate $\chi^{2}$ test was used where appropriate (Statistica 8 software, license for Medical University of Lodz, Poland). Results were considered statistically significant if $\mathrm{p}<0.05$.

\section{Results}

Renal biopsy showed that among studied cases 38 biopsies (50\%) met histological criteria of non-diabetic renal disease (group I), 11 biopsies (14.5\%) were found to have non-diabetic renal disease superimposed on underlying diabetic nephropathy (group II), and 27 biopsies (35.5\%) showed isolated diabetic nephropathy (group III) (Fig. 1). Clinical and laboratory data in the three studied groups are shown in Table I. Males outnumbered females in all groups. Patients in group I had an average age of $58.2 \pm 9.8$ years, whereas patients in group II had an average age of $59.4 \pm 10.3$ years, and those in group III had an average age of $60.6 \pm 8.1$ years. No statistically significant differences were detected between the three 
groups in the age at the time of biopsy, the incidence of hypertension, nephrotic syndrome and BMI value. The duration of diabetes was significantly shorter in group I than in groups II and III (NDRD vs. NDRD + DN p $<0.001 ;$ NDRD vs. DN p $<0.001$, respectively). The prevalence of diabetic retinopathy prior to renal biopsy was significantly lower in NDRD patients than in patients with evidence of DN $(\mathrm{p}<0.03)$. Urinary protein excretion was significantly lower in patients with NDRD than in patients with NDRD + DN, as well as in patients with DN ( $\mathrm{p}<0.04$, and $\mathrm{p}<0.001$, respectively). Microhematuria occurred in $57.9 \%$ of patients with NDRD and in $33.3 \%$ of patients with DN ( $<<0.04)$. Mean GFR was significantly lower in patients with evidence of DN than in NDRD and NDRD + DN groups ( $\mathrm{p}<0.006$, and $\mathrm{p}<0.03$, respectively). Histopathological findings in NDRD patients are shown in Table II. Focal segmental glomerulosclerosis (FSGS) (Figs. 2, 3) was the most common histopathological finding, accounting for $34.2 \%$ of all the NDRD, followed by membranous nephropathy (Figs. 4, 5), IgA nephropathy, glomerulonephritis with crescents, and minimal change glomerulopathy. In renal biopsies belonging to group II the most common pathological findings superimposed on underlying DG was FSGS $(45.5 \%)$, followed by membranous nephropathy (36.4\%), and interstitial nephritis (18.1\%). Among 27 biopsies with evidence of diabetic glomerulosclerosis histological evaluation revealed class III diabetic nephropathy (nodular sclerosis, Kimmelstiel-Wilson

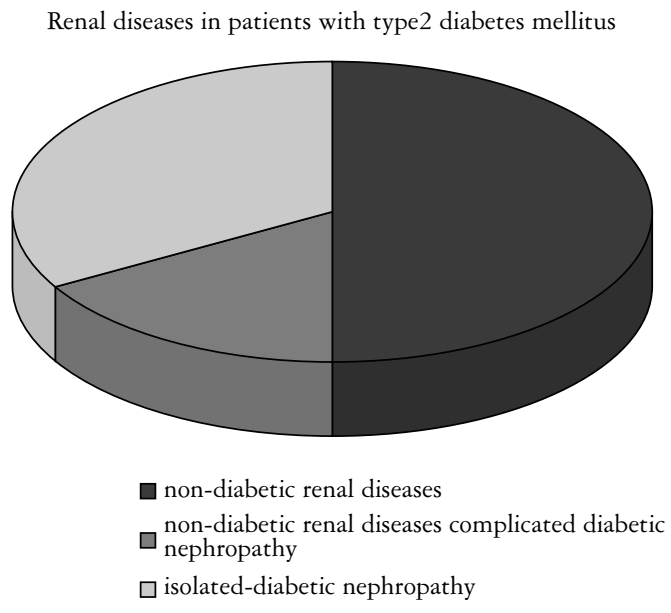

Fig. 1. Biopsy-proven renal diseases in patients with type 2 diabetes mellitus

Table I. Clinical and laboratory data in the three studied groups in diabetic patients

\begin{tabular}{|c|c|c|c|c|}
\hline Parameters & $\begin{array}{l}\text { GROUP I } \\
(\text { NDRD }) \\
(\mathrm{N}=38) \\
\end{array}$ & $\begin{array}{c}\text { GROUP II } \\
(\mathrm{NDRD}+\mathrm{DN}) \\
(\mathrm{N}=11)\end{array}$ & $\begin{array}{l}\text { Group III } \\
(\mathrm{DN}) \\
(\mathrm{N}=27) \\
\end{array}$ & P-value \\
\hline Age (years) & $58.2 \pm 9.8$ & $59.4 \pm 10.3$ & $60.6 \pm 8.1$ & NS \\
\hline Gender $(\mathrm{M} / \mathrm{F})$ & 26/12 & $8 / 3$ & $16 / 11$ & \\
\hline $\begin{array}{l}\text { Duration of diabetes } \\
\text { (years) }\end{array}$ & $5.8 \pm 2.3$ & $9.2 \pm 3.8$ & $10.3 \pm 4.8$ & $\begin{array}{c}\text { group I vs. group II }<0.001 \\
\text { group I vs. group III } \\
<0.001\end{array}$ \\
\hline Diabetic retinopathy $(\%)$ & 42.1 & 54.5 & 70.4 & $\begin{array}{l}\text { group I vs. group II } \\
\text { NS } \\
\text { group I vs. group III } \\
<0.03\end{array}$ \\
\hline Hypertension (\%) & 94.7 & 100 & 100 & NS \\
\hline $\mathrm{BMI}>25(\%)$ & 89.5 & 90.9 & 100 & NS \\
\hline Nephrotic syndrome (\%) & 65.8 & 72.7 & 70.4 & NS \\
\hline Mean proteinuria $\mathrm{g} / 24 \mathrm{~h}$ & $5.2 \pm 2.2$ & $7.9 \pm 3.7$ & $8.7 \pm 5.1$ & $\begin{array}{l}\text { group I vs. group II } \\
<0.04 \\
\text { group I vs. group III } \\
<0.001\end{array}$ \\
\hline Microhematuria (\%) & 57.9 & 45.5 & 33.3 & $\begin{array}{c}\text { group I vs. group III } \\
<0.04\end{array}$ \\
\hline $\begin{array}{l}\text { Mean e-GFR } \\
\mathrm{ml} / \mathrm{min} / 1.73 \mathrm{~m}^{2}\end{array}$ & $44.7 \pm 10.3$ & $36.2 \pm 12.6$ & $35.6 \pm 15.2$ & $\begin{array}{l}\text { group I vs. group II } \\
<0.03 \\
\text { group I vs. group III } \\
<0.006\end{array}$ \\
\hline
\end{tabular}




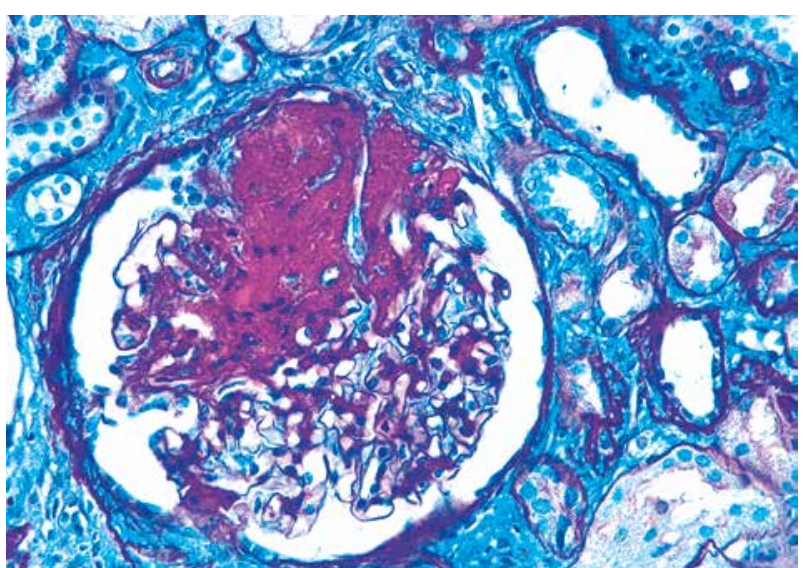

Fig. 2. Focal segmental glomerulosclerosis in patients with type 2 diabetes mellitus. Segmental lesion contains acellular PAS-positive deposit within collapsed glomerular capillaries. PAS staining. Magnification $400 \times$

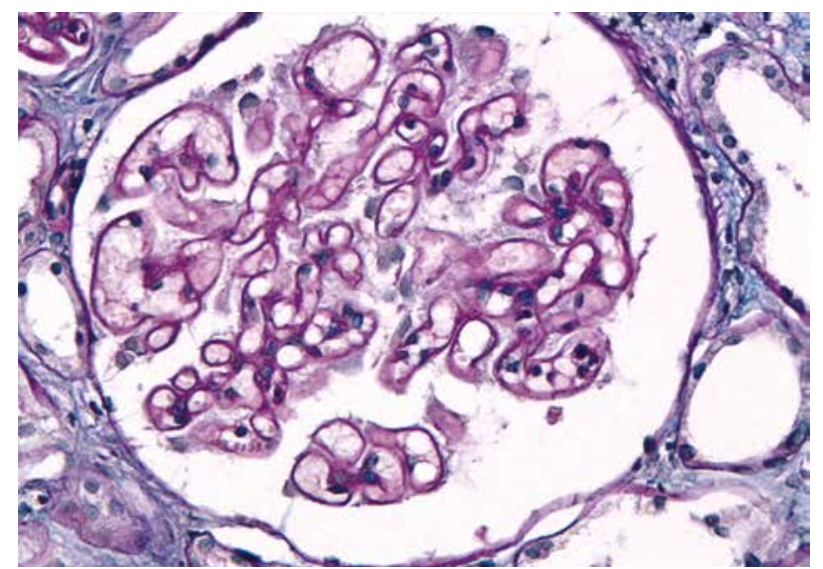

Fig. 4. Membranous nephropathy in patient with type 2 diabetes mellitus. PAS staining shows thickening of the glomerular basement membrane. Magnification $400 \times$

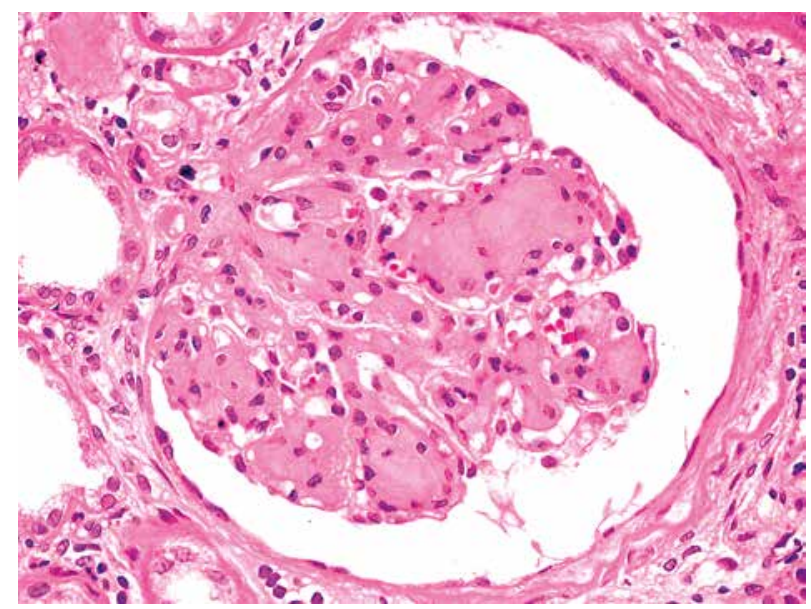

Fig. 6. Classic Kimmelstiel-Wilson nodules in a biopsy from a patient with type 2 diabetes mellitus (class III of pathologic classification of diabetic nephropathy). HE staining. Magnification $400 \times$

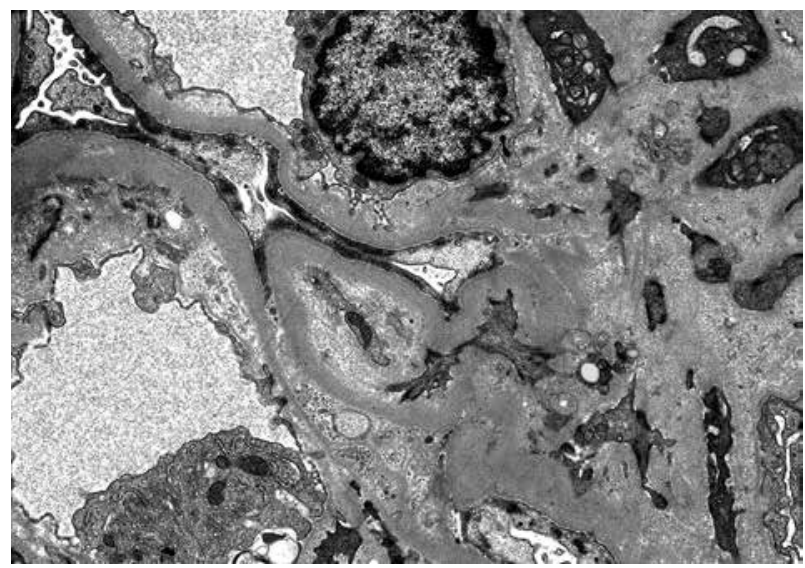

Fig. 3. Focal segmental glomerulosclerosis in patient with type 2 diabetes mellitus. Electron micrograph shows segmental sclerosis and diffuse podocyte foot process effacement. Magnification $10000 \times$

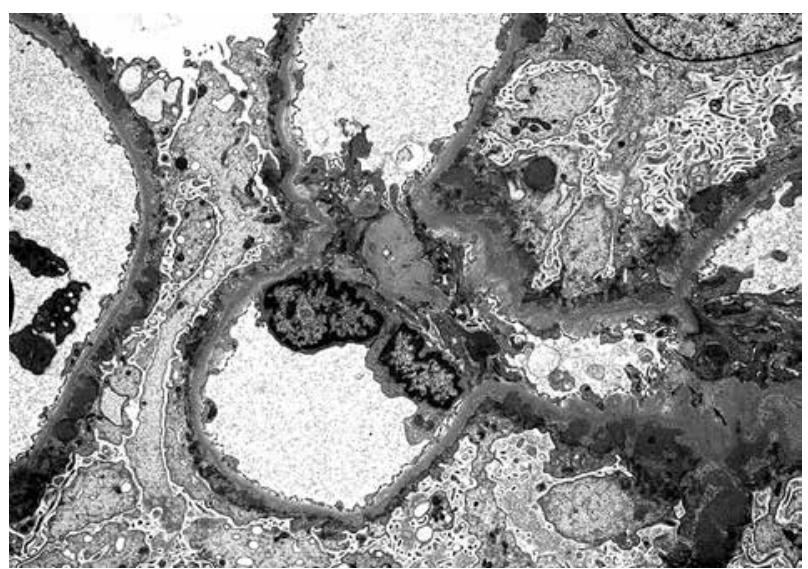

Fig. 5. Membranous nephropathy in patient with type $2 \mathrm{di}-$ abetes mellitus. Electron microscopy shows subepithelial deposits consistent with Ehrenreich-Churg stages I and II and podocyte foot process effacement. Magnification 5000×

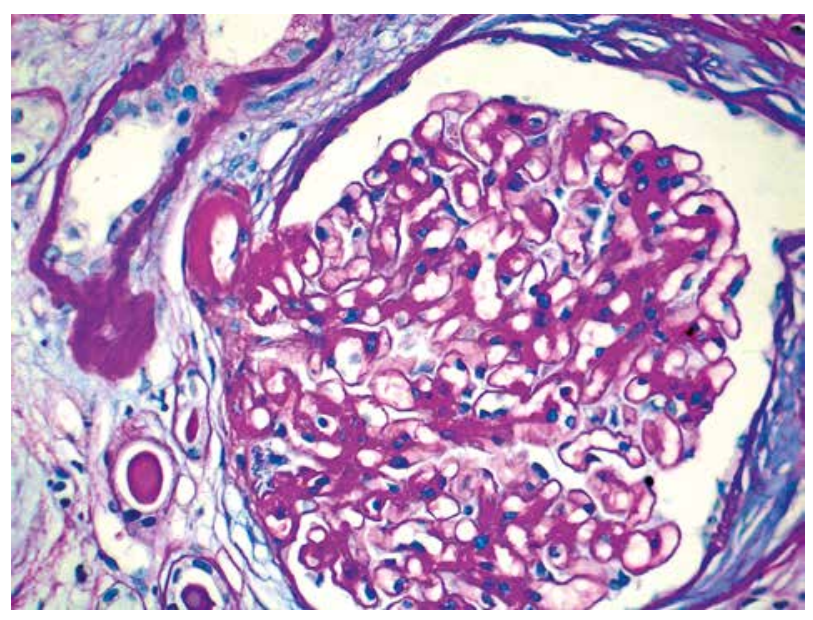

Fig. 7. Renal biopsy in patient with type 2 diabetes mellitus. Enlarged glomerulus with diffuse mesangial sclerosis (class II b of pathologic classification of diabetic nephropathy). Arteriolar hyaline insudation characteristic for diabetic nephropathy is seen. PAS staining. Magnification $400 \times$ 
lesions) in 11 cases $(40.7 \%)$ (Fig. 6), class II b (severe mesangial expansion) in 8 cases (29.6\%) (Fig. 7), and class IV (advanced diabetic glomerulosclerosis) in 6 cases $(22.2 \%)$. Class I and class IIa of diabetic nephropathy were rarely seen in the renal tissue.

\section{Discussion}

In this study, renal biopsy findings showed that one-half of patients with type 2 diabetes had non-diabetic renal disease, $14.5 \%$ of patients had non-diabetic renal disease superimposed on diabetic nephropathy, whereas $35.5 \%$ of patients had isolated diabetic nephropathy. This is in accordance with previous studies of others where the prevalence of NDRD was found to range from $35 \%$ to $57 \%[7,14$, 15]. However, it must be taken into consideration that our results may overestimate the true number of patients with NDRD, because patients were initially selected for renal biopsy owing to a high suspicion of NDRD.

In accordance with other studies, our results showed the preponderance of males in all studied groups $[5,6,16,17]$. There were no differences in the patient's age at the time of biopsy, the value of $\mathrm{BMI}$, the incidence of hypertension or the incidence of nephrotic syndrome between the three studied groups. In diabetic patients the diagnosis of diabetic nephropathy is almost always based on the presence of diabetic retinopathy, hypertension, progressive decline in renal function and persistent proteinuria without hematuria. It is thought that the validity of this approach is well established in type 1 diabetes mellitus, but not in those with type 2 diabetes [5]. Our study showed that patients with NDRD had shorter duration of diabetes than patients in groups II and III. This is in concordance with Soni et al. [5], whereas Bertani et al. [18] did not observe a significant difference in the duration of diabetes between NDRD and DN groups. Regarding laboratory parameters in studied groups, our study revealed that in NDRD patients the incidence of microhematuria was higher, whereas protein excretion was lower in comparison with patients with biopsy-proven DN (group III). Mean GFR was significantly lower in patients with evidence of DN than in NDRD and NDRD + DN groups. Nair and Said [19] and Rychlik et al. [20] concluded that lower proteinuria was observed to be significant in NDRD, whereas Soni et al. [21] revealed that sudden onset of nephrotic proteinuria strongly suggested NDRD.

Our study showed that the incidence of diabetic retinopathy in the NDRD group was lower than in the isolated DN group. However, it must be stressed that about $30 \%$ of patients with biopsy-proven diabetic glomerulosclerosis did not have retinopathy. Several studies suggest that the absence of retinopa-
Table II. Histopathological findings in non-diabetic renal disease (NDRD) group

\begin{tabular}{lcc}
\hline Pathologic DiAgNOSIS & $\begin{array}{c}\text { Number } \\
\text { OF CASES }\end{array}$ & $\begin{array}{c}\text { PerCENTAGE } \\
(\%)\end{array}$ \\
\hline FSGS & 13 & 34.2 \\
\hline Membranous nephropathy & 8 & 21.1 \\
\hline IgA nephropathy & 6 & 15.8 \\
\hline GN with crescents & 5 & 13.2 \\
\hline MCD & 2 & 5.3 \\
\hline MPGN type I & 1 & 2.6 \\
\hline Fibrillary GN & 1 & 2.6 \\
\hline LCDD & 1 & 2.6 \\
\hline Amyloidosis & 1 & 2.6 \\
\hline $\begin{array}{l}\text { FSGS - focal segmental glomerulosclerosis; } \text { GN - glomerulonephritis; } \\
\text { MCD - minimal change disease; } \text { MPGN - mesangioproliferative glomerulone- } \\
\text { phritis; LCDD - light chain deposition disease }\end{array}$ &
\end{tabular}

thy is a strong predictor of NDRD [7, 22, 23, 24]. In contrast, the study of Prakash et al. [8] demonstrated that presence or absence of diabetic retinopathy was a poor predictor of diabetic nephropathy, because DN was noted in $50 \%$ of patients without diabetic retinopathy and $40 \%$ of patients with diabetic retinopathy had NDRD either alone or in combination with DN. In our study, statistical analysis revealed a significant difference in the incidence of microhematuria between the studied groups, but it must be highlighted that microhematuria was also present in $33 \%$ of patients with biopsy-proven DN. Kharrat et al. [25] found that the presence of hematuria and the absence of diabetic retinopathy correlate with NDRD in diabetic patients. Wilfred et al. [26] found that absence of retinopathy and presence of microscopic hematuria and active urinary sediment had positive predictive value for NDRD in diabetic patients. Mak et al. [27] and Matias et al. [28] found a strong correlation between NDRD and microscopic hematuria, whereas Serra et al. [22] reported that DN was most commonly found in diabetic patients manifesting microscopic hematuria. In the study of Yaqub et al. [29] there was no difference in the prevalence of microscopic hematuria among isolated NDRD and NDRD superimposed on underlying DN. A study of Tone $e t$ al. [7] showed that microscopic hematuria had lower sensitivity and specificity for the prediction of NDRD compared with the other parameters, suggesting that microscopic hematuria is not a good predictor of NDRD. Taken together, these facts may suggest that laboratory and clinical data do not always accurately predict NDRD in diabetes patients; thus performing the renal biopsy in patients with type 2 diabetes mellitus is mandatory. It must be stressed that differentiating non-diabetic glomerular disease from diabetic 
renal disease in early stages may be difficult. Olsen [30] stated that in such cases it is hazardous to make the diagnosis of glomerulonephritis based on light microscopy alone; immunofluorescence microscopy should always be added to the investigation, and optimally also electron microscopy. It is obvious that early diagnosis and management of NDRD in diabetics is important because these patients have significantly better outcomes compared to biopsy-proven diabetic glomerulosclerosis.

With regard to renal biopsy findings in our study, FSGS was the most prevalent type of NDRD, followed by membranous nephropathy, IgA nephropathy and crescentic glomerulonephritis. Similarly to our results, the most common lesion in the US was focal and segmental glomerular sclerosis [31]. In other studies $\operatorname{Ig} A$ nephropathy and minimal change disease were found to be the commonest NDRD [32, 33]. It must be taken into consideration that the incidence and type of renal involvement depend on biopsy criteria and geographical distribution. Studies from Korea and China reported $\operatorname{IgA}$ nephropathy as the commonest NDRD, accounting for $59 \%$ of patients $[33,34,35]$. Our study showed that FSGS and membranous nephropathy was also the most common pathologic finding superimposed on underlying DN. The diagnosis of nondiabetic renal disease complicated by diabetes is important for the treatment of renal disease. The differences in the prevalence patterns of glomerulopathies in diabetic patients may be related to the racial predispositions for specific glomerulopathies. It is well known that FSGS is the most common primary glomerulopathy in non-diabetic adults in Poland, whereas IgA nephropathy is observed in up to $40 \%$ of all biopsies performed for glomerular disease in Asia. The pathogenesis of NDRD in diabetic patients is not clear. Some authors have suggested that the predisposition of DN to glomerulonephritis could be attributed to enhanced exposure of antigenic cellular components, triggering immune responses [36].

Histological evaluation in the DN group revealed that class III was the commonest glomerular lesion of diabetic nephropathy. This observation is in accordance with others [37]. Nodular type of diabetic nephropathy is regarded as further development of the diffuse type. Nodules are formed from mesangial matrix, and they occur later in the disease than the diffuse lesions. It is thought that nodules never occur without associated marked diffuse lesions. Widening of the mesangial matrix and thickening of the peripheral glomerular basement membrane - the first ultrastructural lesion - can be identified 2-3 years after onset of diabetes mellitus [38]. It is well known that the early changes can usually not be seen by light microscopy until several years of diabetes. The differential diagnosis of nodular diabetic glomerulosclerosis is wide and includes membranoproliferative glomerulonephritis, membranous glomerulonephritis, and other immune complex glomerulopathies, monoclonal immunoglobulin deposition disease, cryoglobulinemic glomerulonephritis, fibronectin glomerulonephritis, hypertensive nephropathy, fibrillary and immunotactoid glomerulopathies, amyloidosis, and idiopathic nodular glomerulosclerosis $[39,40,41]$. The accurate diagnosis of glomerular lesions requires immunofluorescence evaluation and electron microscopy study of renal tissue. Moreover, a close clinicopathological correlation is mandatory to diagnose diabetic nephropathy.

In summary, the present study demonstrated the heterogeneous pattern of injury in renal tissue in patients with type 2 diabetes mellitus and renal involvement. Non-diabetic renal disease is a common feature in diabetics. Differentiating NDRD from DN on the basis of clinical and laboratory parameters is difficult; however, hematuria, short duration of diabetes and absence of diabetic retinopathy in type 2 diabetic patients manifesting renal involvement may indicate NDRD. Our study revealed that renal biopsy should be performed in diabetics for determining the pattern of renal injury. The accurate diagnosis of glomerular injury in patients with diabetes should include the examination of renal tissue by light microscope, immunofluorescence and electron microscopy.

The authors declare no conflict of interest.

This work was supported by grant 503/6038-01/50301 of the Medical University of Lodz.

\section{References}

1. Ritz E, Zeng XX, Rychlík I, et al. Clinical manifestation and natural history of diabetic nephropathy. Nontrib Nephrol 2011; 170: 19-27

2. Wild S, Roglic G, Green A, et al. Global prevalence of diabetes: estimates for year 2000 and projections for 2030. Diabetes Care 2004; 27: 1047-1053.

3. Wiggins RC. The spectrum of podocytopaties: a unifying view of glomerular diseases. Kidney Int 2007; 71: 1205-1214.

4. Ruggenenti P, Gambara V, Perna A, et al. The nephropathy of non-insulin-dependent diabetes: Predictors of outcome relative to diverse pattern of renal injury. J Am Soc Nephrol 1998; 9: 2336-2343.

5. Soni SS, Gowrishankar S, Kishan AG, et al. Non-diabetic renal disease in type 2 diabetes mellitus. Nephrology 2006; 11: 533 537.

6. Pham TT, Sim JJ, Kujubu DA, et al. Prevalence of nondiabetic renal disease in diabetic patients. Am J Nephrol 2007; 27 : 322-328.

7. Tone A, Shikata K, Matsuda M, et al. Clinical features of non-diabetic renal diseases in patient with type 2 diabetes. Diabetes Res Clin Pract 2005; 69: 237-242.

8. Prakash J, Sen D, Usha, Kumar NS. Non-diabetic renal disease in patients with type 2 diabetes mellitus. J Assoc Physicians India 2001; 49: 415-420.

9. Lin YL, Peng SJ, Ferng SH, et al. Clinical indicators with necessitate renal biopsy in type 2 diabetes mellitus patients with renal disease. Int J Clin Pract 2009; 63: 1167-1176. 
10. Mazzucco G, Bertani T, Fortunato M, et al. Different patterns of renal damage in type 2 diabetes mellitus: A multicentric study on 393 biopsies. Am J Kidney Dis 2002; 39: 713-720.

11. Yoshikawa Y, Truong LD, Mattioli CA, et al. Membranous glomerulonephritis in diabetic patients: A study of 15 cases and review of the literature. Mod Pathol 1990; 3: 36-42.

12. Tervaert TW, Mooyaart AL, Amann K, et al. Pathologic classification of diabetic nephropathy. J Am Soc Nephrol 2010; 21: 556-563.

13. Colvin RB, Chang A, Kambham N, et al. Glomerular Diseases In: Diagnostic Pathology Kidney Diseases. Colvin RB (eds.) $1^{\text {st }}$ ed. Amirsys Publishing, Inc. Canada 2011; 2.2-358.

14. Huang F, Yang Q, Chen L, et al. Renal pathological changes in patients with type 2 diabetes are not always diabetic nephropathy: A report of 52 cases. Clin Nephrol 2007; 67: 293-297.

15. Gambara V, Mecca G, Remuzzi G, et al. Heterogenous nature of renal lesions in type II diabetes. J Am Soc Nephrol 1993; 3 : 1458-1466.

16. Ghani AA, Waheeb SA, Sahow AA, et al. Renal biopsy in patients with type 2 diabetes mellitus: Indications and nature of the lesions. Ann Saudi Med 2009; 29: 450-453.

17. Bi H, Chen N, Ling G, et al. Nondiabetic renal disease in type 2 diabetic patients: a review of our experience in 220 cases. Ren Fail 2011; 33: 26-30.

18. Bertani T, Mecca G, Sacchi G, et al. Superimposed nephritis: A separate entity among glomerular diseases? Am J Kidney Dis 1986; 7: 2015-212.

19. Nair R, Said M. Diabetic woman with massive proteinuria and acute renal failure. Am J Kidney Dis 2005; 46: 362-366.

20. Rychlik T, Jancova E, Tesar V. Non-diabetic renal disease among diabetic patients undergoing renal biopsy 5-year results of The Czech Registry (CRRB). $3^{\text {rd }}$ World Congress of Nephrology Brussels. International Society of Nephrology (ISN); 2005.

21. Soni SS, Swanalatha G, Kishen AG, et al. Predictors of non-diabetic renal disease in type 2 diabetes mellitus; South Indian experience. Nephrology 2005; 10 (Suppl): A18.

22. Serra A, Romero R, Bayes B, et al. Is there a need for changes in renal biopsy criteria in proteinuria in type 2 diabetes? Diabetes Res Clin Pract 2002; 58: 149-153.

23. Christensen PK, Larsen S, Horn T, et al. Causes of albuminuria in patients with type 2 diabetes without diabetic retinopathy. Kidney Int 2000; 58: 1719-1731.

24. Haddiya I, Hamzaoui $\mathrm{H}$, Al Hamany Z, et al. Isolated non diabetic renal disease in diabetic patients: a Maroccan report Saudi J Kidney Dis Transpl 2009; 21: 555-558.

25. Kharrat M, Kammoun K, Charfeddine K, et al. Renal biopsy findings in diabetes mellitus. Tunis Med 2007; 85: 216-219.

26. Wilfred DC, Mysorekar VV, Venkataramana RS, et al. Nondiabetic renal disease in type 2 diabetes mellitus patients: A clinicopathological study. J Lab Physicians 2013; 5: 94-99.

27. Mak SK, Gwi E, Chan KW, et al. Clinical predictors of non-diabetic renal disease in patients with non-insulin dependent diabetes mellitus. Nephrol Dial Transpl 1997; 12: 2588-2591.

28. Matias P, Viana H, Carvalho F, et al. Diabetes mellitus and renal disease: when to perform a renal biopsy? Port Nephrol Hypert 2009; 23: 167-73.

29. Yaqub S, Kashif W, Hussain SA. Non-diabetic renal disease in patients with type-2 diabetes mellitus. Saudi J Kidney Dis Transpl 2012; 23: 1000-1007.

30. Olsen S. Identification of non-diabetic glomerular disease in renal biopsies from diabetics- a dilemma. Nephrol Dial Transplant 1999; 14: 1846-1849.

31. Nzerue CM, Hewan-Lowe K, Harvey P, et al. Prevalence of non-diabetic renal disease among African-American patients with type II diabetes mellitus. Scand J Urol Nephrol 2000; 34 : 331-335.
32. Das U, Dakshinamutry KV, Prayaga A, et al. Nondiabetic kidney disease in type 2 diabetic patients: A single center experience. Indian J Nephrol 2012; 22: 358-362.

33. Lee EY, Chung CH, Choi SO. on-diabetic renal disease in patients with non-insulin dependent diabetes mellitus. Yonsei Med J 1999; 40: 321-326.

34. Zhuo L, Zou G, Li W, et al. Prevalence of diabetic nephropathy complicating non-diabetic renal disease among Chinese patients with type 2 diabetes mellitus. Eur J Med Res 2013; 22: 4 .

35. Li H, Li XW, Huang QY, et al. Non-diabetic renal disease in type II diabetes mellitus. Zhongguo Yi Xue Ke Xue Yuan Xue Bao 2003; 25: 101-104.

36. Orfila C, Lepert JC, Modesto A, et al. IgA nephropathy complicating diabetic glomerulosclerosis. Nephron 1998; 79: 279287

37. Zhu X, Liu F, Peng Y, et al. New pathologic classification of diabetic nephropathy (retrospective study of 37 cases). ZhongNan Da Xue Xue Bao Yi Xue Ban 2012; 37: 185-189.

38. Osterby R. Early phases of in the development of diabetic glomerulopathy. A quantitative electron microscopic study. Acta Med Scand 1975; (suppl 574) (thesis).

39. Alsaad KO, Herzenberg AM. Distinguishing diabetic nephropathy from other causes of glomerulosclerosis: an update. J Clin Pathol 2006; 60: 18-26.

40. Wróblewski K, Sodolska M, Wągrowska-Danilewicz M, et al. When "diabetic nephropathy" is not always of diabetic origin: a case report. Pol J Pathol 2012; 63: 134-137.

41. Hałoń A. Zmiany w nerkach w chorobach metabolicznych. Pol J Pathol 2011; 1 (Suppl.1): s72-s81.

\section{Address of correspondence}

Małgorzata Wagrowska-Danilewicz MD, $\mathrm{PhD}$

Department of Nephropathology, Medical University of Lodz Pomorska 251

92-216 Lodz, Poland

tel./fax +48 426757633

e-mail: malgorzata.wagrowska-danilewicz@umed.lodz.pl 